\title{
ISTILAH-ISTILAH PERKEBUNAN PADA MASYARAKAT MADURA
}

\author{
Kiki Tristanti \\ Program Studi Pendidikan Bahasa dan Sastra Indonesia \\ Fakultas Keguruan dan IImu Pendidikan \\ Universitas Muhammadiyah Jember \\ kikitristanti11@gmail.com
}

DOI: $\underline{\text { http://dx.doi.org/10.32528/bb.v4i2.2558 }}$

Diterima: 12 September 2018

Diterbitkan: 30 Oktober 2019

\begin{abstract}
ABSTRAK
Artikel ini membahas bentuk-bentuk, penggunaan dan makna istilah bahasa Madura pada bidang perkebunan. Penelitian ini merupakan jenis penelitian kualitatif deskriptif. Data diperoleh melalui wawancara yang dilengkapi dengan teknik dasar pancing. Teknik lanjutan yang digunakan adalah teknik cakap semuka yang dilanjutkan dengan teknik catat. Analisis data menggunakan metode padan intralingual dan metode padan ekstralingual yang dilanjutkan dengan metode deskriptif. Data diklasifikasikan atas beberapa bentuk yaitu:nomina, verba, ajektiva dan frasa. Data berupa nomina terdiri atas nomina dasar, nomina turunan, nomina tempat, dan nomina kuantita dan penggolong. Data berupa verba terdiri atas verba asal dan verba turunan. Berdasarkan ada tidaknya nomina yang mendampinginya, data berupa verba terdiri atas verba kausatif. Secara semantik, data yang dianalisis memiliki makna istilah antara lain berupa makna khusus, makna deskriptif, dan makna refensial. Berdasarkan penggunaannya, dihasilkan bentukbentuk istilah yang secara etnolinguistik hanya digunakan dan dapat dipahami oleh masyarakat pemilik budaya dan pengguna bahasa tersebut.
\end{abstract}

Kata Kunci: Istilah, Perkebunan, bahasa Madura, Etnolinguistik

\section{ABSTRACT}

This article discusses the forms, use and meaning of the terms in Madurese language related to plantations. This research is a descriptive qualitative research. The data are obtained through interviews. The follow up techniques were face to face interaction and note taking. The data analysis employed a unified intralingual method and unified extralingual method followed by descriptive methods. Data were classifed into several forms; nouns, verbs, adjectives and phrases. The data consist of a noun form, the noun base, derivative nouns, noun place, and quantitative nouns and classifiers. The data in the form of the verb consist of verbs and derivative verbs. Based on the presence or absence of accompanying noun, the data in the form of verbs consists of transitive and intransitive verbs, while based on its meaning, the data in the form of verbs consist of the causative verb. Semantically, the data analyzed have term meaning, exceptional meaning, descriptive meaning and referential meaning. Based on the usage, the forms are entholinguistically, which means the terms can only be used and understood by the those who live with the culture and use the lamguage.

Keywoard:Term, Plantation, Madura language, Ethnolinguistic 


\section{PENDAHULUAN}

Bangsa Indonesia merupakan bangsa multikultural yang kaya akan keragaman budaya. Budaya sebagai tata nilai dan norma memerlukan media representasi agar pembedaan pemahaman nilai-nilai budaya yang muncul dapat diintegrasi dan diadaptasi dengan baik tanpa mengesampingkan nilai-nilai dan kepentingan bersama. Salah satu media yang representatif untuk mewujudkan hal tersebut adalah bahasa. Bahasa yang merupakan salah satu unsur kebudayaan universal (Koentjaraningrat, 1990:203-204) memiliki peran penting dalam kehidupan masyarakat penggunanya. Aplikasi bahasa dalam kebudayaan menjadikan bahasa sebagai media yang paling representatif bagi pemilik kebudayaan. Menurut Keraf (1980:3) setidaknya terdapat beberapa fungsi bahasa, yaitu: (1) bahasa sebagai alat menyatakan ekspresi diri, (2) bahasa sebagai alat komunikasi, (3) bahasa sebagai alat untuk mengadakan integrasi dan adaptasi sosial, dan (4) bahasa sebagai alat untuk kontrol sosial.

Beragamnya budaya, juga memunculkan berbagai macam bahasa sebagai alat berinteraksi dan berkomunikasi antar penggunanya. Bahasabahasa tersebut antara lain berup bahasa daerah seperti bahasa Jawa, bahasa Sunda, bahasa Batak, dan bahasa Madura. Bahasa-bahasa tersebut memiliki ciri-ciri dan keunikan masing-masing. Misalnya dalam bahasa Madura (selanjutnya disingkat BM), terdapat kata ikan yang dalam Bahasa Indonesia (selanjutnya disingkat BI) merujuk pada jenis binatang yang hidup di air dan biasanya dapat dijadikan sebagai lauk. Arti tersebut dipahami secara konvensional dan tidak dapat menunjuk pada jenis lain yang hidupnya di darat seperti kadal dan lain-lain. Kata ikan dalam BI sangat berbeda jauh jika dibandingkan dengan pemahaman masyarakat yang dalam kesehariannya menggunakan BM. Masyarakat Madura memaksudkan ikan dengan kata jhuko' yang tidak hanya merujuk pada ikan namun dapat juga merujuk pada daging dan lain-lain. Bahkan masyarakat Madura menyebut jhuko' untuk semua lauk termasuk tempe, tahu, dan lain-lain.

Contoh lain terdapat pada kata soklin yang dalam Bahasa Indonesia merujuk pada diterjen dengan merk soklin. Secara konvensional kata soklin tidak bisa menunjuk pada merk yang lain tapi bagi masyarakat Madura soklin yang merujuk pada merk 'diterjen' dapat menunjuk diterjen dengan merk lain seperti bukrim, daia dan surf. Masyarakat Madura memiliki pemahaman bahwa antara bukrim, daia, dan surf, yang merujuk pada diterjen adalah jenis diterjen dengan merk yang sama sehingga dalam kesehariannya masyarakat Madura memilih menggunakan kata soklin untuk menunjuk merk dari diterjen yang lain.

Bentuk keunikan yang didasarkan pada suatu bentuk kebudayaan tersebut kemudian dipelajari dalam suatu studi kebahasaan yaitu etnolinguistik yang oleh Soeparno (2002:25) didefinisikan sebagai sub-disiplin linguistik yang mempelajari bahasa dalam kaitannya dengan faktor-faktor etnis dan budayanya. Hal tersebut juga dapat menjadi indikator bahwa bahasa memiliki korelasi yang kuat dengan kebudayaan. Kebudayaan sebagai suatu sistem yang mengatur pola kehidupan bermasyarakat memerlukan pentingnya suatu sarana interpretasi berupa bahasa termasuk BM yang menjadi objek pembahasan pada penelitian ini.

Untuk memahami bahasa, Koentjaraningrat menggunakan sesuatu yang disebutnya "kerangka kebudayaan", yaitu memiliki dua aspek tolak yaitu (1) wujud kebudayaan, dan (2) isi kebudayaan. Wujud kebudayaan dapat berupa gagasan, prilaku, dan fisik atau benda. Sementara isi kebudayaan terdiri dari unsur yang bersifat universal, artinya unsur tersebut terdapat dalam setiap masyarakat manusia yang ada di dunia. Unsur-unsur tersebut oleh Koentjraningrat (1990:203-204) dibagi menjadi tujuh unsur, yaitu: (1) bahasa, (2) sistem teknologi, (3) sistem pencaharian hidup atau ekonomi, (4) organisasi sosial, (5) sistem pengetahuan, (6) sistem religi, (7) kesenian.

Penelitian ini fokus pada masalah (1) Mendeskripsikan bentuk, penggunaan dan makna istilah-istilah yang digunakan dalam bidang perkebunan pada tahap pembibitan. (2) Mendeskripsikan bentuk, penggunaan dan makna istilah-istilah yang digunakan dalam bidang perkebunan pada tahap perawatan. (3) Mendeskripsikan bentuk, penggunaan dan makna istilah-istilah yang digunakan dalam bidang perkebunan pada tahap penyadapan. (4) Mendeskripsikan bentuk, penggunaan dan makna istilah-istilah yang digunakan dalam bidang perkebunan pada tahap pengolahan atau produksi.

Sesuai dengan focus penelitian yang ada, tujuan yang hendak dicapai dalam penelitian ini adalah mendeskripsikan bentuk-bentuk, pengunaan, dan makna istilah perkebunan pada masyarakat Madura di Desa Harjomulyo, Kecamatan Silo, Kabupaten Jember. Penelitian ini diharapkan dapat dijadikan sebagai pedoman atau sumber rujukan untuk penelitian sejenis dengan kajian yang lebih luas lagi, khusunya BM, Penelitian ini juga diharapkan dapat membantu masyarakat, khususnya masyarakat Madura untuk memahami istilah-istilah yang digunakan dalam bidang perkebunan baik secara teoritis maupun aplikatif. 


\section{METHDE PENELITIAN}

Metode yang digunakan dalam penelitian ini melalui tiga tahap, (1) tahap penyediaan data, (2) tahap analisis data; dan (3) tahap penyajian analisis data. Metode penyediaan data dan tekniknya dalam penelitian ini melalui cara wawancara yang dilanjutkan dengan teknik dasar pancing (lihat Sudaryanto, 1993:137). Teknik lanjutan yang digunakan berupa teknik cakap semuka yang dilanjukan dengan teknik catat. Peneliti mencatat segala bentuk tuturan yang dapat dijadikan sebagai data. Data dianalisis menggunakan metode padan berupa metode padan intralingual dan metode padan ekstralingual. Data yang dianalisis kemudian disajikan dengan menggunakan metode formal dan metode informal.

\section{PEMBAHASAN}

Istilah-istilah perkebunan yang digunakan oleh masyarakat Madura di Desa Harjomulyo, Kecamatan Silo, Kabupaten Jember dapat diklasifikasi berdasarkan beberapa tahapan. Tahapan-tahapan tersebut adalah (1) Istilah-istilah perkebunan yang didasarkan pada tahap pembibitan, (2) Istilah-istilah perkebunan yang didasarkan pada tahap pemeliharaan, (3) Istilahistilah perkebunan yang didasarkan pada tahap penyadapan atau sadap, dan (4) Istilah-istilah perkebunan yang didasarkan pada tahap pengolahan getah atau produksi.

1.Tahap pembibitan ditemukan istilah, antara lain: elsebe, karet, bidingan, nembhuk, matar, metter, camba, mata kalemmar, kompos, tello pajung, klon, lilit batang, karet pote, keni' bhungka, entres, semaktah, nabu', ramo', ramo' gheseng, dan ngalle.

2.Tahap pemeliharaan dilakukan sebanyak dua kali. Tahap pertama dimulai dari matar bibit karet sampai proses pemindahan ke gulutan. Tahap kedua dilakukan sejak bibit karet di gulutan sampai waktu sadap. Istilah yang terdapat pada tahap pertama antara lain, gulutan, nyeram, juringan,sellang, panyolaman, bhungka, baba, sambhungan, ketebbhung, ember, selbhi', mata daun, mata sesse', guru', laddhing, ghangsean, ngolet, yiyit, kellet, nyokkla', lare', ngangsel, perreng tale, mal, nganjhir, ajhir, budu'an, dan kopala. Sedangkan istilah yang terdapat pada tahap kedua antara lain, pepel, are', rawisan, slubu'an, ajumrit, panjang, bumes, embun tepong, nyabhuk, landuk, dan guru'.

3.Tahap penyadapan atau sadap yaitu mengambil getah dari pohon karet. Pada tahap ini ditemukan istilah-istilah antara lain, sadap, ngeres, ghetta, patek, manko', bisu', tatal,andha, tekote, ngokot, pellet, juldhung, ember, juldung, ghetta tana, settripan, pekolan, takeran, canteng conto, manko' conto, cokka, tembhangan, juleng, koco', los, pensiun, mandur sadap, mandur besar, asisten, sendar, dan jurtoles.

4.Tahap pengolahan yaitu tahap mengolah getah menjadi barang setengah jadi. Pada tahap pengolahan ditemukan istilah yang diklasifikasi berdasarkan proses pengolahan yaitu pengolahan getah atau lateks dan pengolahan lump. Pada proses pengolahan getah atau lateks ditemukan istilah antara lain, ledeng, bak sheet, pellat, mesin ghiling sheet, lori, ajhemmor/pangasapan, tomang, mera kaleng, sortasi, pressan, dan bel. Sedangkan pada proses pengolahan lump ditemukan beberapa istilah antara lain, kapo', drim, mesin ghiling lump, browncrepe, dan ajhemmor.

\subsection{Bentuk-bentuk, Penggunaan, dan Makna Istilah Perkebunan}

Berdasarkan bentuknya, istilah-istilah perkebunan pada masyarakat Madura terdiri atas nomina, verba, ajektiva dan frasa.

1) Nomina

Bentuk-bentuk istilah berupa nomina terdiri atas nomina dasar, nomina turunan, nomina tempat, dan nomina kuantita dan penggolong.

a) Nomina Dasar

Istilah-istilah yang berbentuk nomina dasar antara lain, élsébé, karét, cambâ, klon, ramo', sellang, émbér, selbhi', guru', laddhing, yiyit, lare', gulutan, panjang, bumes, landuk, patek, manko', bisu', tatal, andha, tekote, pellet, juldhung, ember, bidingan, dan ajir.

Elsebe [elsebe] digunakan untuk menyebut jenis bibit karet yang dijadikan sambhungan atau bibit okulasi. Dalam kamus BM tidak ditemukan istilah elsebe yang semakna dengan pengertian di atas. Kata elsebe hanya dapat ditemui dalam kamus $\mathrm{BI}$ dengan makna merujuk pada jenis bibit dengan pengertian tersebut. Hanya secara fonetis bentuk penulisannya sangat berbeda. Pada masyarakat Madura jenis bibit tersebut ditulis elsebe (ortografis), sedangkan dalam $\mathrm{BI}$ elsebe ditulis dengan LCB. Berdasarkan pernyataan tersebut istilah elsebe dapat diklasifikasi sebagai nomina dasar.

Pengklasifikasian di atas berdasarkan pada ciri-ciri nomina yaitu (1) memiliki kecenderungan untuk menduduki posisi subjek, objek, atau pelengkap kalimat yang predikatnya berupa verba. (2) dapat dijadikan bentuk ingkar yang menggunakan kata banne 'bukan', tetapi tidak dapat dijadikan bentuk ingkar yang menggunakan kata ta' 'tidak' dan 'jha' 'jangan', dan (3) biasanya dapat diikuti oleh ajektiva baik secara langsung maupun dengan perantaraan kata se 'yang' (Sofyan, dkk, 2008:126). 
Secara semantik. Elsebe dapat diklasifikasi sebagai nomina dengan makna khusus yaitu makna yang tetap dan pasti. Ketetapan dan kepastian makna tersebut disebabkan oleh penggunaannya yang hanya terdapat pada bidang kegiatan atau keilmuan tertentu (Peteda, 2001:106). Jadi, tanpa berada dalam konteks kalimat pun makna untuk istilah tersebut sudah pasti. Elsebe tidak akan ditemui pada bidang yang lain dengan bentuk dan pengertian yang sama. Berdasarkan pengertian tersebut, elsebe juga dapat diklasifikasi sebagai nomina dengan makna referensial (referential meaning) yaitu makna langsung berhubungan acuan yang ditunjuk oleh kata. Referensi atau acuan dapat berupa benda, peristiwa, proses, atau kenyataan (Peteda, 2001:125). Elsebe mempunyai acuan yang menunjuk 'bibit karet yang dijadikan sambhungan atau bibit okulasi'.

\section{b) Nomina Turunan}

Istilah-istilah yang berbentuk nomina turunan antara lain, pekolan, settripan dan sambhungan. Pekolan [pekolan] digunakan untuk menyebut nama alat pikul ghetta yang ada di juldhung untuk di bawa ke takeran. Dalam kamus BM, pekolan merupakan nomina yang bernakna 'pikulan' muatan yang dipikul, sebatang kayu untuk memikul (Pawitra, 2009:534).

Secara semantik, pekolan mempunyai makna referensial (referential meaning) yaitu makna yang langsung berhubungan dengan acuan yang ditunjuk oleh kata. Bentuk-bentuknya dapat berupa benda, peristiwa, proses, sifat, dan kenyataan (Pateda, 2001:125). Pada istilah pekolan makna menmgacu pada alat yang digunakan untuk memikul ghetta yang ada di juldhung'.

Settripan [setripan] digunakan untuk menyebut ghetta kering yang menempel di jalur sadap. Dalam kamus BM, hanya ditemukan bentuk dasar dari settripan berupa settrip 'jalur' (Pawitra, 2009:653). Dari pengertian tersebut dapat dijelaskan bahwa settripan merupakan bentuk nomina turunan. Settripan berasal dari bentuk dasar settrip yang mendapat ombihan berupa sufiks $\{-a n\}$, sehinnga menjadi settripan. Secara semantik, settripan mempunyai makna khusus yaitu makna yang tetap dan pasti. Ketetapan dan kepastian makna istilah tersebut disebabkan oleh penggunaannya yang hanya terdapat pada bidang kegiatan dan keilmuan tertentu (Pateda, 2001:106). Jadi, tanpa berada dalam konteks kalimat pun makna istilah tersebut sudah pasti.

Settripan juga dapat diklasifikasi sebagai nomina dengan makna referensial (referential meaning) yaitu makna yang langsung berhubungan dengan acuan yang ditunjuk oleh kata. Bentukbentuknya dapat berupa benda, peristiwa, proses, sifat, dan kenyataan (Pateda, 2001:125). Settripan mengacu pada 'getah kering yang berasal dari jalur sadap'.

c) Nomina Tempat

Istilah-istilah yang berbentuk nomina tempat antara lain, ghangsean, juringan, dan tembhangan. Ghangsean [ghangsean] adalah istilah yang digunakan untuk menyebut benda untuk mengasah bisuk. Dalam kamus BM, ghangsean mempunyai makna 'alat atau tempat untuk mengasah' (Pawitra, 2009:181). Ghangsean merupakan nomina turunan yang berasal dari verba ghangse 'asah' yang mendapat imbuhan berupa sufiks $\{$-an\} sehinnga menjadi menjadi nomina turunan ghangsean 'sesuatu yang di...' secara semantik, ghangsean mempunyai makna referensial (referential meaning) yaitu makna yang langsung berhubungan dengan acuan yang ditunjuk oleh kata. Bentukbentuknya dapat berupa benda, peristiwa, proses, sifat, dan kenyataan (Pateda, 2001:125). Pada istilah ghangsean makna referensial mengacu pada benda atau alat yang digunakan untuk mengasah bisuk.

d) Nomina Kuantita dan Penggolong

Istilah-istilah yang berbentuk nomina kuantita dan penggolong antara lain budu'an, dan kopala. budu'an [budu?an] digunakan untuk menyebut anjhir yang ditancapkan ketika nganjhir pohon karet di gulutan yang mempunyai ukuran kecil. Ukuran budu'an biasanya kurang lebih $80 \mathrm{~cm}$ dan ditancapkan pada lubang tanam. Dalam kamus BM tidak ditemukan adanya istilah budu'an. Berdasarkan bentuknya, budu'an dapat diklasifikasi sebagai nomina turunan dari bentuk kata dasar budu' yang berarti [anak' dengan imbuhan berupa \{-an\}. Bentuk kata dasar berupa kata kerja yang mendapat sufiks $\{-a n\}$ akan menjadi kata benda dengan arti 'tempat atau alat'. Istilah budu'an seperti pengertian tersebut dapat diklasifikasi sebagai nomina turunan dengan arti menunjuk pada 'alat' berupa anjhir yang ditancapkan ketika nganjhir pohon karet gulutan yang mempunyai ukuran kecil.

Berdasarkan penggunaannya, budu'an dapat diklasifikasi sebagai nomina kuantita dan penggolong. Hal ini didasarkan pada istilah budu'an yang dimaksudkan untuk menyebut jenis alat berupa anjhir yang ukurannya lebih kecil dari jenis anjhir kopala. Semua anjhir yang ukurannya lebih kecil dan biasanya digunakan untuk meluruskan bibit karet yamg memiliki tinggi kurang lebih $80 \mathrm{~cm}$, maka dapat digolongkan pada anjhir budu'an atau budu'an.

Secara semantik, budu'an mempunyai makna khusus yaitu makna yang tetap dan pasti. ketetapan dan kepastian makna istilah tersebut disebabkan oleh penggunaannya yang hanya terdapat pada bidang kegiatan atau keilmuan 
tertentu (Pateda, 2001:106). Jadi, tanpa berada dalam konteks kalimat pun makna istilah tersebut sudah pasti. Budu'an tidak akan ditemui pada bidang yang lain dengan bentuk dan pengertian yang sama.

Kopala [kopala] digunakan untuk menunjuk nama anjhir yang ditancapkan ketika nganjhir pohon karet dilahan tanam atau kebun. Ukuran kopala biasanya kurang lebih 3 meter, tergantung pada tinggi diinginkan Kopala ditancapkan di cokkla'an dengan garis lurus baik panjang atau lebarnya. Dalam kamus BM tidak ditemukan adanya istilah kopala. Berdasarkan bentuknya kopala dapat diklasifikasi sebagai nomina dasar istilah kopala mempunyai makna 'alat' berupa anjir dengan ukuran kurang lebih 2,5 meter. Fungsi kopala yaitu untuk meluruskan pohon karet yang sudah besar'.

Berdasarkan penggunaannya, kopala dapat diklasifikasi sebagai nomina kuantita dan penggolong. Hal itu didasarkan pada istilah kopala yang dimaksudkan untuk menyebut jenis alat berupa anjhir yang ukurannya lebih besar dari jenis anjhir budu'an. Semua anjhir yang ukurannya lebih besar dan biasanya digunakan untuk meluruskan bibit karet yang memiliki tinggi kurang lebih 2,5 meter, dapat diklasifikasi sebagai anjhir kopala. Secara semantik, pengertian tersebut menyimpulkan bahwa istilah kopala mempunyai makna khusus yaitu makna yang tetap dan pasti. Ketetapan dan kepastian makna istilah tersebut disebabkan oleh penggunaannya yang hanya terdapat pada bidang kegiatan atau keilmuan tertentu (Pateda, 2001:106). Jadi, tanpa berada dalam konteks kalimat pun makna istilah tersebut sudah pasti. Kopala tidak akan ditemui pada bidang yang lain dengan pengertian yang sama, meskipun terdapat istilah kopaladengan maksud 'ketua atau yang menjadi pemimpin'.

\section{2) Verba}

Berdasarkan bentuknya, istilah-istilah berupa verba terdiri atas verba asal dan verba turunan.

a) Verba Asal

Istilah berupa verba asal antara lain, metter, entres, congke', cottak, mal, pepel, rawisan, sadap, dan sortasi. Sedangkan istilah yang berupa verba turunan antara lain, nembhuk, matar, nabu', ngalle', nyeram, ngolet, nyokla', ngangsel, nganjir, ajumrit, nyabhuk, ngeres, ngokot, ajhemmor/pengasapan, dan ajhemmor. Berdasarkan ada tidaknya nomina yang mendampinginya, verba dapat berupa verba transitif seperti nganjhir, ngangsel, dan nyabhuk. Sedangkan istilah berupa verba intransitif seperti ngeres, mal, dan rawisan. Berdasarkan maknanya, ditemukan istilah berupa verba kuasatif dan refleksif. Verba refleksif seperti istilah metter.
Entres [entres] adalah istilah yang digunakan untuk menyebut pekerjaan dengan cara memilih bibit karet yang akan disambung. Dalam kamus BM tidak ditemukan adanya istilah entres. Berdasarkan bentuknya, istilah entres dapat dikategorikan sebagai verba asal yaitu verba yang berupa bentuk tunggal tanpa digabungkan dengan satuan gramatik yang lain, tapi sudah memiliki makna leksikal (Sofyan, dkk, 2008:126). Pernyataan tersebut menunjukkan bahwa istilah entres adalah istilah yang diperoleh secara konvensional masyarakat dan hanya memiliki oleh masyarakat pengguna bahasa tersebut.

Berdasarkan ada tidaknya nomina, entres dapat diklasifikasi sebagai verba intransitif yaitu verba yang tidak didampingi atau memerlukan nomina. Dalam hubungannya dengan nomina, entres diklasifikasi sebagai verba aktif yaitu verba yang subjeknya berperan sebagai pelaku. Berdasarkan maknanya, entres dapat diklasifikasi sebagai verba kausatif yaitu verba yang menyatakan perbuatan 'menyebabkan menjadi'. Sesuai dengan pengertian tersebut, entres mempunyai makna dengan bentuk pernyataan 'menyebabkan terpilih'.

Secara semantik, entres mempunyai makna khusus yaitu makna yang tetap dan pasti. Ketetapan dan kepastian makna tersebut disebabkan oleh penggunaannya yang hanya terdapat pada bidang kegiatan atau keilmuan tertentu (Pateda, 2001:106). Jadi, tanpa berada dalam konteks kalimat pun makna untuk istilah tersebut sudah pasti. Entres tidak akan ditemui pada bidang yang lain dengan bentuk dan pengertian yang sama.

b) Verba Turunan

Nganjhir [nanjhir] adalah istilah yang digunakan untuk menyebut pekerjaan yang dilakukan untuk memberi anjhir pada pohon karet yang sudah ditanam disetiap cokkla'. Nganjhir dilakukan untuk meluruskan pohon karet, dan biasanya menggunakan perreng. Nganjhir pohon karet dilakukan sebanyak dua kali, yaitu nganjhir pada saat pohon ada di gulutan, dan nganjhir pada saat pohon karet ada di lahan tanam atau sudah dipindah dari gulutan ke lahan tanam.

Nganjhir berasal dari kata dasar anjhir yang mendapatkan prefiks $\{\mathrm{N}-\}$, sehingga menjadi nganjhir yang berarti 'memergunakan atau bekerja dengan yang disebut oleh bentuk dasar'. Berdasarkan ada tidaknya nomina, nganjhir dapat digolongkan sebagai verba transitif yaitu verba yang didampingi nomina atau memerlukan nomina sebagai objek dalam kalimat aktif (Sofyan, dkk, 2008:126).

Berdasarkan maknanya, nganjhir dapat diklasifikasi sebagai verba kuasatif. Secara semantik, nganjhir mempunyai makna referensial 
(referential meaning) yaitu makna yang langsung berhubungan dengan acuan yang ditunjuk oleh kata. Menurut Pateda (2001:125) acuan atau referen dapat berupa benda, peristiwa, proses, sifat, dan kenyataan. Pada istilah nganjhir makna yang di acu berupa proses yaitu menandai dan meluruskan pohon karet dengan menggunakan anjhir.

Nganjhir juga mempunyai makna khusus yaitu makna yang tetap dan pasti. Ketetapan dan kepastian makna istilah tersebut disebabkan oleh penggunaannya yang hanya terdapat pada bidang kegiatan atau keilmuan tertentu (Pateda, 2001:106). Jadi, tanpa berada dalam konteks kalimat pun makna istilah tersebut sudah pasti nganjhir tidak akan ditemui pada bidang yang lain dengan bentuk dan pengertian yang sama.

Mal [mal] adalah istilah yang digunakan untuk menyebut pekerjaan untuk mengukur lilit batang pohon karet yang ada di lahan tanam. Mal dilakukan dengan menggunakan alat ukur yang disebut okoran. Mal dilakukan dengan mengukur lilit batang ukuran kurang lebih $50 \mathrm{~cm}$ dan tinggi 2,5 meter. Dalam kamus BM, mal mempunyai makna 'dana' harta benda berupa uang atau barang, model (contoh)'(Pawitra,2009:398).

Berdasarkan bentuknya, mal dapat diklasifikasi sebagai verba asal. Berdasarkan ada tidaknya nomina yang mendampingi atau membutuhkan objek dan tidaknya, mal dapat diklasifikasi sebagai verba intransitif. Berdasarkan hubungannya dengan nomina, mal dapat diklasifikasi sebagai verba aktif, sedangkan bila didasarkan pada maknanya, mal dapat diklasifikasi sebagai verba kuasatif denga bentuk pernyataan 'menjadikan bibit karet terukur baik lilit batang ataupun tingginya'.

Secara semantik, mal mempunyai makna khusus yaitu makna yang tetap dan pasti. Ketetapan dan kepastian makna istilah tersebut disebabkan oleh penggunaannya yang hanya terdapat pada bidang kegiatan atau keilmuan tertentu (Pateda, 2001:106). Jadi, tanpa berada dalam konteks kalimat pun makna istilah tersebut sudah pasti. Dalam kamus BM, mal mempunyai beberapa makna yaitu (1) dana: harta benda berupa uang atau barang, dan (2) model (contoh) (Pawitra, 2009:398). Sementara mal dalam bidang perkebunan mempunyai makna 'mengukur yaitu pekerjaan mengukur lilit batang pohon karet yang ada di lahan tanam'.

Berdasarkan maknanya, ditemukan istilah berupa verba kuasatif antara lain, ngeres, nyeram, nyabhuk, ngokot, nembhuk, dan sortasi. Dalam kamus BM, ngeres [neres] mempunyai makna 'mengiris' (Pawitra, 2009:162). Ngeres berasal dari bentuk verba pangkal eres 'iris', potong karet' yang mendapat imbuhan berupa prefiks $\{\mathrm{N}-\}$ dengan makna 'melakukan suatu perbuatan yang disebut bentuk pangkal'. Berdasarkan maknanya, ngeres dapat diklasifikasi sebagai verba kausatif dengan bentuk pernyataan 'menyebabkan teriris'. Secara semantik, ngeres mempunyai makna khusus yaitu makna yang tetap dan pasti. Ketetapan dan kepastian makna istilah tersebut disebabkan oleh penggunaannya yang hanya terdapat pada bidang kegiatan atau keilmuan tertentu (Pateda, 2001:106). Jadi, tanpa berada dalam konteks kalimat pun makna istilah tersebut sudah pasti.

3) Ajektiva

Istilah yang berupa ajektiva antara lain, jhurbhu, kellet, elop, dan ghumbhus. Jhurbhu [jhurbhu] merupakan istilahyang digunakan untuk menandai bibit karet dengan pertumbuhan yang cepat atau tumbuh subur. Dalam kamus BM jhurbhu bermakna 'cepat besar atau tumbuh tinggi dengan cepat' (Pawitra, 2009:242). Berdasarkan bentuknya, jhurbhu dapat diklasifikasi sebagai ajektiva bertaraf yang menyatakan 'agak' dengan tanda abak, seperti abak jhurbhu, dan menyatakan 'sangat' dengan tanda parana, seperti parana jhurbhu 'sangat cepat pertumbuhannya'.

Secara semantik, jhurnhu dapat diklasifikasi sebagai ajektiva dengan makna deskriptif yaitu makna yang biasa disebut makna kognitif atau makna referensial. Makna deskriptif adalah makna yang berlangsung berhubungan dengan acuan yang ditunjuk oleh kata. Jhurbhu mengacu pada 'bibit karet yang pertumbuhannya cepat atau tumbuh subur'.

Elop [elop] adalah istilah yang digunakan untuk menyebut pohon yang layu. Dalam kamus $\mathrm{BM}$, elop mempunyai makna 'layu atau lisut yaitu tentang bunga atau daun yang tidak segar lagi dan ada tanda-tanda akan mengering' (Pawitra, 2009:154). Berdasarkan bentuknya, elop dapat diklasifikasi sebagai ajektiva. Elop merupakan ajektiva dasar yaitu ajektiva yang berupa bentuk tunggal. Berdasarkan maknanya, elop dapat diklasifikasi sebagai ajektiva bertaraf yang menyatakan 'agak' dengan tanda abak, seperti abak elop, dan menyatakan 'hampir' dengan tanda para'...a, seperti para' elopa ghallu 'hampir terlalu layu'.

Secara semantik, elop dapat diklasifikasi sebagai ajektiva dengan makna referensial (referential meaning) yaitu makna yang langsung berhubungan dengan acuan yang ditunjuk oleh kata. Bentuk-bentuknya dapat berupa benda, peristiwa proses, sifat, dan kenyataan (Pateda, 2001:125). Pada kata elop makna mengacu pada 'pohon karet yang layu'.

4) Frasa 
Sementara untuk frasa ditemukan istilah antara lain , canteng conto, mangko' conto, mesin ghiling sheet, mera kaleng, mesin ghiling lump, dan brown crepe. Canteng conto [canten conto] digunakan untuk menyebut canting yang digunakan untuk menakar ukuran bagus tidaknya ghetta yang diperoleh. Dalam kamus BM tidak ditemukan istilah yang semakna dengan canteng conto. Berdasarkan bentuknya, canteng conto berasal dari kata canteng dan conto. Canteng bermakna 'canting (gayung, penyiduk) alat untuk menciduk air' (Pawitra, 2009:102). Conto bermakna 'contoh (sesuatu yang akan atau yang disediakan untuk ditiru atau diikuti)' (Pawitra, 2009:121). Canteng conto dapat diklasifikasi sebagai jenis frasa endosentris.

Dilihat dari segi letak unsur inti dan pewatasnya, canteng conto dapat diklasifikasi sebagai frasa endosentris dengan konstruksi inti ditambah pewatas kanan (konstruksi DM). Canteng conto terdiri dari dua bentuk kata dasar yaitu canteng dan conto. Unsur pertama adalah canteng yang merupakan unsur inti dan dapat mewakili semua unsur frasa. Unsur inti canteng dalam kamus BM merupakan bentuk nomina dengan makna 'canting: gayung, penyiduk, sebagai alat untuk menciduk air' (Pawitra, 2009:102). Canteng merupakan kata yang diterangkan oleh unsur pewatas. Karena pewatas terletak di sebelah kanan unsur inti, unsur pewatas ini disebut pewatas kanan. Berdasarkan letakn unsur inti dan pewatasnya, canteng conto mempunyai makna 'canting yang dijadikan sebagai conto'.

Konstruksi di atas dalam BM disebut konstruksi frasa endosentris atributif dengan unsur pusat (UP) kata benda. Pada konstruksi frasa endosentris atributif, canteng conto diklasifikasikan sebagai frasa endosentris atributif dengan pola kata benda + kata benda. Secara semantik, canteng conto mempunyai makna khusus yaitu makna yang tetap dan pasti. Ketetapan dan kepastian makna istilah tersebut disebabkan oleh penggunaannya yang hanya terdapat pada bidang kegiatan atau keilmuan tertentu (Pateda, 2001:106).

Canteng conto juga mempunyai makna referensial (referential meaning) yaitu makna yang langsung berhubungan dengan acuan yang ditunjuk oleh kata. Bentuk-bentuknya dapat berupa benda, peristiwa, proses, sifat, dan kenyataan (Pateda, 2001:125). Canteng conto mengacu pada 'canting yang dijadikan sebagai conto'.

Berdasarkan penggunaannya, istilah-istilah yang dianalisis memiliki penggunaan yang sifatnya khas, seperti pada istilah ajhemmor dan brown crepe. Ajhemmor yang pertama digunakan untuk menyebut proses pengeringan lembaran getah yang sudah digiling agar menjadi lembaran yang kering atau sheet. Ajhemmor ini dilakukan dengan cara mengasapkan lembaran getah di atas tungku kurang lebih 4 hari dan hanya dilakukan untuk menjemur getah lateks.

Ajhemmor yang kedua digunakan untuk mengeringkan lembaran brown crepe atau jenis getah lump. Ajhemmor ini dilakukan dengan cara menganginkan brown crepe kurang lebih 1 bulan dan hanya dilakukan untuk menjemur getah lump. Jadi ajhemmor memiliki dua pengertian dengan penggunaan dan maksud yang berbeda. Orang akan mengatakan ajhemmor dengan maksud mengasapkan jika yang akan dijemur adalah getah lateks, dan akan mengatakan ajhemmor dengan maksud menganginkan jika yang dijemur adalah getah lump.

Pengertian di atas berbeda dengan pengertian secara umum, dimana ajhemmor 'menjemur' dipahami sebagai aktivitas yang dilakukan dengan cara menjemur sesuatu di bawah sinar matahari. Demikian juga dengan istilah brown crepe yang digunakan untuk menyebut jenis getah lump atau getah yang berasal dari busa getah asli. Brown crepe memiliki jenis yaitu brown crepe $2 X$ (berwarna putih bening), 3X (berwarna agak gelap), 5X (berwarna hitam atau biasa disebut black crepe). Pengertian tersebut berbeda dengan pengertian brown crepe yang diartikan sebagai kain krep atau kain sutera tipis yang berwarna coklat.

Secara semantik, bentuk-bentuk istilah di atas diklasifikasi pada beberapa jenis makna yaitu makna khusus, makna deskriptif, dan makna referensial.

\section{SIMPULAN}

Berdasarkan pada hasil penelitian dan pembahasan masalah yang telah diuraikan dapat diambil kesimpulan bahwa istilah perkebunan pada masyarakat Madura dapat diklasifikasi berdasarkan bentuk, penggunaan dan maknanya. Berdasarkan bentuknya, ditemukan beberapa istilah berupa nomina, verba dan ajektiva dan frasa. Istilah-istilah berupa nomina terdiri atas nomina dasar, nomina turunan, nomina tempat, dan nomina kuantita dan penggolong.

Istilah-istilah berupa verba berdasarkan bentuknya diklasifikasi atas verba asal dan verba turunan. Berdasarkan ada tidaknya nomina yang mendampinginya, verba terdiri atas verba transitif dan verba intransitif. Sedangkan berdasarkan maknanya, dihasilkan istilah berupa verba kausatif. Secara semantik, makna istilah yang telah dianalisis terdiri atas makna khusus, makna deskriptif, dan makna referensial. Beberapa istilah merupakan bahasa konvensional yang khas, sehingga bentuk, penggunaan, dan maknanya berbeda walaupun terdiri dari kosa kata yang sama, seperti ajhemmor dan brown crepe. 


\section{DAFTAR RUJUKAN}

Akhmad Sofyan, Bambang Wibisono, Amir Mahmud, dan Foriyani Subiyatningsih. 2008. Tata Bahasa Madura. Sidoarjo: Balat Bahasa Surabaya.

Daryanto. 1997. Kamus Bahasa Indonesia Lengkap. Surabaya: Apollo.

Djajasudarma, Fatimah. 1993. Metode Linguistik (Ancangan Metode Penelitian dan Kajian). Bandung. Eresco.

Keraf, Gorys. 1980. Tata Bahasa Indonesia. Ende Flores: Nusa Indah.

Koentjaraningrat. 1990. Pengantar Ilmu Antropologi. Jakarta: Rineka Cipta. Pateda. Mansoer. 2001. Semantik Leksikal. Jakarta: Rineka Cipta.

Pawitra, Adrian. 2009, Kamus Lengkap Bahasa Madura Indonesia (Dengan Ejaan Bahasa Madura Tepat Ucap). Jakarta: Dian Rakyat.

Sudaryanto. 1993. Metode dan Aneka Teknik Analisis Bahasa (Pengantar Penelitian Wahana Kebudayaan secara Linguis). Yogyakarta: Duta Wacana University Press.

Soeparno. 2002. Dasar-dasar Linguistik Umum Yogyakarta: Tiara Wacana.

Pateda, Mansoer. 2001. Semantik Leksikal. Jakarta. Rineka Cipta. 